\title{
Maternal infection by Leishmania braziliensis in hamster does not influence the course of disease in progeny
}

\section{A infecção materna por Leishmania braziliensis em hamster não influencia o curso da doença na prole}

Lia Fernandes Alves Lima ${ }^{1}$, Mércia Sindeaux Frutuoso ${ }^{2}$, Augusto César Aragão Oliveira ${ }^{3}$, Webertty Mayk Eufrásio de Figueiredo $^{4}$, Margarida Maria de Lima Pompeu ${ }^{5}$, Maria Jania Teixeira ${ }^{5}$

1. Médica do Hospital Geral de Fortaleza, Fortaleza, Ceará, Brasil. 2. Centro Universitário Christus (UNICHRISTUS), Fortaleza, Ceará, Brasil. 3. Pós-graduando, RENOBIO - Universidade Federal do Ceará, Fortaleza, Ceará, Brasil. 4. Pós-graduação - DINTER - Universidade Federal do Ceará - Fiocruz/RJ, Brasil. 5. Docente da Faculdade de Medicina, Universidade Federal do Ceará, Fortaleza, Ceará, Brasil.

\begin{abstract}
Introduction: Immunoglobulins, soluble antigens, cells, cytokines and other immune system products can be transferred from infected mother to her offspring, leading to suppression or stimulation of immune response. Objective: To evaluate the influence of gender and maternal infection with Leishmania braziliensis in the course of the disease in the offspring of hamsters. Methods: Offspring born from infected mother (IMO) or non-infected mother (NIMO) by Leishmania braziliensis, both sexes, was infected with the same strain of the mother after 30 days of life and followed for 18 weeks. We evaluated the thickness of the lesion, parasite load and histology of the lesions. Results: The number of parasite in both lesions and lymph node of IMO offspring showed a significant reduction in the 5th week post-infection compared to the NIMO offspring; however, this did not correspond to clinical symptoms. Histopathological analysis revealed that in the IMO offspring, the inflammatory process was more prominent. In relation to gender, it was observed that the male offspring showed lesion thickness and higher parasite burden than females. Conclusion: Maternal infection by L. braziliensis in hamsters does not appear to influence the course of the disease in the homologous offspring infection, as well as the male offspring presented augmented susceptibility to $L$. braziliensis infection regardless of whether they were born from IMO or NIMO. Also, the reduction of the granuloma index in the IMO offspring, together with the higher inflammatory response, suggests a less effective cellular response in the chronic phase of the disease in these animals.
\end{abstract}

Key words: Leishmania braziliensis. Maternal infection. Gender. Hamster. Histopathology.

\section{Resumo}

Introdução: Imunoglobulinas, antígenos solúveis, células, citocinas e outros produtos do sistema imune podem ser transferidos de mãe infectada para a sua prole, levando à supressão ou estimulação da resposta imune. Objetivo: Avaliar a influência do gênero e a infecção materna por Leishmania braziliensis no curso da doença na prole de hamsters. Métodos: Filhotes nascidos de mãe infectada (MI) e mãe não infectada (MNI) por L. braziliensis, ambos os sexos, foram infectados com a mesma cepa da mãe após 30 dias de vida e acompanhados por 18 semanas. Avaliou-se a espessura da lesão, a carga parasitária e os aspectos histopatológicos das lesões. Resultados: A carga parasitária (lesões e linfonodo de drenagem das lesões) da prole nascida de MI mostrou diminuição significativa na 5 a semana pós-infecção, comparada àquela nascida de MNI, no entanto, esta diminuição não correspondeu aos sintomas clínicos. A análise histopatológica revelou que na prole nascida de MI, o processo inflamatório mostrou-se mais proeminente. Em relação ao gênero observou-se que os filhotes machos apresentaram espessura das lesões e carga parasitária maiores do que as fêmeas. Conclusão: A infecção materna por L. braziliensis parece não influenciar o curso da doença na infecção homóloga da prole, bem como os filhotes machos apresentaram aumentada susceptibilidade à infecção por L. braziliensis, independente se eles nasceram de MI ou MNI. Além disso, a redução no index de granulomas na prole nascida de MI, em conjunto com a maior resposta inflamatória, sugere uma resposta celular menos efetiva na fase crônica da doença nestes animais.

Palavras-chave: Leishmania braziliensis. Infecção Materna. Gênero. Hamster. Histopatologia.

\section{INTRODUCTION}

Leishmaniasis is a parasitic infection due to protozoans of the genus Leishmania that can manifest different clinical forms: tegumentary form (localized cutaneous, mucocutaneous and diffuse cutaneous) and the visceral form, depending on the Leishmania species involved ${ }^{1}$. In Ceará state, Brazil, human tegumentary forms have as its main etiological agent L. braziliensis ${ }^{2}$, species known to develop cases of localized cutaneous Leishmaniasis ( $\mathrm{LCL}$ ), with one to multiple ulcerated lesions and also mucocutaneous involvement, and in the latter case, the oropharynx mucosa is compromised and morbidity rates are high $^{3}$.

The LCL form, caused by L. braziliensis, may result in regional lymphadenopathy preceding the formation of lesions in one to twelve weeks, named "Bubonic Form" and originally described in Brazil/4,5. The diagnostic framework is usually based on unspecific symptoms such as asthenia, anorexia, weight loss and low fever. As the ulcerated lesions develop the unspecific 
symptoms and lymphadenopathy tends to regress ${ }^{4}$.

The immunological interaction between mother and fetus in any infection is complex. The possible passage of soluble factors, such as antigens, may induce an immunological response in the fetus due to an infection homologous to a maternal one, resulting in suppression or stimulation of the immune response, leading, respectively, to a progression or limitation of the infection ${ }^{6}$. Studies on C57BL/6 mice infected with L. major indicated that pregnant females had reduced levels of estrogen associated with an increased susceptibility to the parasite?

Different studies revealed an increased frequency of Leishmaniasis occurrence on males. During Leishmania infection, males have a superior susceptibility and parasitemia than females. Male castration reduces, while exogenous testosterone increases, the infection susceptibility and consequent death of the host ${ }^{8}$. Studies on L. major in mice verified an increased male susceptibility to the infection, characteristically more virulent, as a response to the testosterone effect on the immunosuppression of the cell response ${ }^{9}$.

The experimental model is still the best way to characterize the disease and its impact in the host. The Syrian hamster, Mesocricetus auratus, has been widely used in researches involving tegumentary Leishmaniasis for being susceptible to all species of the Viannia subgenus and for evolving in an infection very similar to the human form, resulting in chronic lesions, with possible metastasis according to the $\operatorname{strain}^{10,11}$.

Herein, it was evaluated the influence of maternal infection and gender by L. braziliensis in hamster in the course of disease in progeny.

\section{MATERIAL AND METHODS}

\section{Animals}

Recently weaned (3- to 4-week old, 40 - to $50 \mathrm{~g}$ ) or adult (3 month old, 100 - to $110 \mathrm{~g}$ ) Syrian hamsters (Mesocricetus auratus) of both genders, obtained from the Central Animal facility of the Departamento de Patologia e Medicina Legal of Universidade Federal do Ceará (DPML/UFC), were used in the experiments. The animals were maintained under standard caging conditions and were provided with commercial rodent food and water ad libitum. The project was approved by CEPA (Comitê de Ética em Pesquisa Animal) at the Universidade Federal do Ceará, under registration number 65/12.

\section{Parasites}

The Leishmania braziliensis strain (MHOM/BR/94/H-3227) was isolated from cutaneous ulcers from patient with cutaneous Leishmaniasis from Ceará state, Brazil. The strain was characterized as L. braziliensis by $\mathrm{PCR}^{12}$. Promastigotes were grown in Schneider's Drosophila medium (Sigma-Aldrich, St. Louis, MO) at $25^{\circ} \mathrm{C}$ supplemented with $20 \%$ fetal bovine serum, $2 \mathrm{mM}$ L-glutamine, antibiotics $(100 \mathrm{U} / \mathrm{mL}$ penicillin and 100 $\mathrm{mg} / \mathrm{mL}$ streptomycin) (all Sigma-Aldrich), and $2 \%$ sterile human urine. The virulence of the strain was maintained by regular passage in a golden hamster. For infection, the parasites were used until the $5^{\text {th }}$ passage in vitro.

\section{Experimental infection}

Female hamsters, 3 month old, were infected subcutaneously in the hind right footpad with $1 \times 10^{6}$ stationary-phase $L$. braziliensis promastigotes in $20 \mu \mathrm{l}$ of sterile saline. After 30 days of infection, females with footpad lesions and a group of healthy females were bred and their offspring were used to create the experimental design. For this experiment, animals were divided in two groups: group 1 consisting of offspring born from mothers infected with L. braziliensis $(n=20)$ and group 2 consisting of offspring born from healthy non-infected mothers $(n=19)$. In each group, an equal male/female ratio was maintained. When the offspring reached 30 days from birth, they were weaned, and infected with the same strain of $L$. braziliensis used to infect the mothers following the same protocol previously described for the mothers.

\section{Clinical and parasitological evaluations}

Lesion sizes were measured weekly during 18 weeks with a dial gauge caliper (Mitutoyo, $0.01 \mathrm{~mm}$ sensitivity) and expressed as the difference between the thicknesses $(\mathrm{mm})$ of the infected and contralateral uninfected footpads. The number of parasites in the draining lymph was quantified by the limiting dilution technique as previously described ${ }^{13}$. Briefly, groups of 8 to 10 animals were euthanized, after 5, 9 and 17 weeks post infection, by inhalation of halothane (Sigma-Aldrich) and submerged in $3 \%$ iodized alcohol up to 3 minutes to allow decontamination. The infected footpad and lymph nodes were removed aseptically and macerated in a Petri dish with $2 \mathrm{~mL}$ of Schneider medium. After removal of debris by sedimentation for $5 \mathrm{~min}$, the homogenates were serially diluted $(1: 10)$ in Schneider's medium supplemented with $100 \mathrm{U} / \mathrm{mL}$ of penicillin/mL, 100 $\mu \mathrm{g} / \mathrm{mL}$ of streptomycin/mL, $10 \%$ fetal bovine serum and $2 \%$ sterile human urine. One hundred microliters of these dilutions was distributed into 96-well flat bottom plates containing agarblood in 6 replicates per concentration. The plates were sealed and incubated at $25^{\circ} \mathrm{C}$ for 3 weeks. The wells were observed on an inverted optical microscope (Nikon) every 3 days to record the dilutions containing promastigotes. The final number of parasites was determined using the ELIDA 12c software.

\section{Evaluation of anti-Leishmania antibodies}

The serum separated from the blood taken from the orbital plexus of the animals was used for the quantification of antiLeishmania antibodies through the immune enzymatic test (ELISA). The ELISA test used was a modification of a procedure reported for use in dogs ${ }^{14}$. Five-period sera were used: before infection, on the $4^{\text {th }}, 8^{\text {th }}, 12^{\text {th }}$ and $17^{\text {th }}$ weeks post infection. Leishmania antigen at the concentration of $10 \mu \mathrm{g} / \mathrm{mL}$ was added 
to flat bottom 96 well plates and incubated at $4^{\circ} \mathrm{C}$ for 18 hours, and then washed after incubation with $4 \%$ PBS. Serum from the animals were added at $1: 100$ dilution and incubated at $37^{\circ} \mathrm{C}$ for 60 minutes. Antibodies were detected by $1: 8000$ diluted peroxidase-conjugated Protein $A$ and the enzyme activated substrate reaction measured in a spectrophotometer at $450 \mathrm{~nm}$ wavelength (Titertek Multiscan, Flow). Each plate contained wells with positive, negative and white (no antigen) controls. The cut off was determined using the mean absorbance of healthy hamster sera (negative control) plus three times the standard deviation.

\section{Histopathological analysis}

Samples were collected from the infected footpads of infected mother (IMO) offspring, non-infected mother (NIMO) offspring, and a group of healthy animals (control, non-infected) at $18^{\text {th }}$ week post infection. Samples were fixed in $10 \%$ neutral buffered formalin, decalcified in $4 \%$ EDTA, processed and mounted in paraffin blocks, sectioned at $5-\mu \mathrm{m}$ intervals, and stained with hematoxylin and eosin for histological analysis. Microscopic alterations were observed and analyzed according to the following parameters: cellular exudate, tissue destruction, eosinophils, neutrophils, lymphocytes, macrophages, giant cells, organized and non-organized granulomas, edema, fibrosis and parasitism. Each parameter was evaluated according to the intensity of the event through scores: 0 (absence), 1 (presence of $1-25 \%$ ), 2 (presence of $25-50 \%$ ), 3 (presence of $>50 \%$ ).

\section{Statistical analysis}

Data are presented as mean \pm standard error of the mean. Data of parasite load; lesion size and histopathology were analyzed using Mann-Whitney test performed in the software GraphPad
Prism, version 6.0 for Windows (GraphPad Software, San Diego, CA, USA). In all tests, the minimum significance was accepted when $\mathrm{P}<0.05$.

\section{RESULTS}

\section{Influence of maternal infection - Lesion size, parasite load and anti-Leishmania antibodies}

The results showed that after the $7^{\text {th }}$ week post-infection, the lesions of offspring born from an infected mother were slightly higher and ulcerated than those born from a non-infected mother, and thus remained until the last observed week, although no statistical significance was found between the data (Fig. $1 \mathrm{~A}$ and $1 \mathrm{~B})$.

Regarding the parasite load, in the $5^{\text {th }}$ week post-infection the number of parasites in both lymph nodes and footpad was significantly lower in the offspring of infected mother compared to offspring of non-infected mother $(p<0.05)$, and such difference was not more observed at the $9^{\text {th }}$ and $17^{\text {th }}$ weeks post-infection (Fig. 2A). Interestingly, lower number of parasites was found in footpad of offspring born from a noninfected mother in the $17^{\text {th }}$ weeks post-infection $(p<0.05)$, when compared to offspring born from an infected mother (Fig. 2B).

Anti-Leishmania antibodies were detected in the sera of both offspring of infected and non-infected mothers in the 4th week post-infection, with mild predominance in offspring of infected mother in the $4^{\text {th }}$ and $8^{\text {th }}$ weeks post-infection. The titers decreases more slowly in offspring of infected mother, providing a statistically significant difference in the 8 th week post-infection (Fig. 3A).

Figure1. Lesion thickness (A) and aspect of the lesions (B) in hamster offspring infected with Leishmania braziliensis, born from infected (IMO) or non-infected mother (NIMO). Each point represents the arithmetic mean \pm standard error of the mean. $\mathrm{N}=20$ (1st to 5th weeks post-infection); $n=16$ ( 7 th and 8th weeks post-infection); $n=12$ (12th to 17th weeks post-infection); $n=6$ (18th week post-infection). The dashed lines represent the normal thickness of 6 healthy animals (basal value). Data are representative of 2 independent experiments.
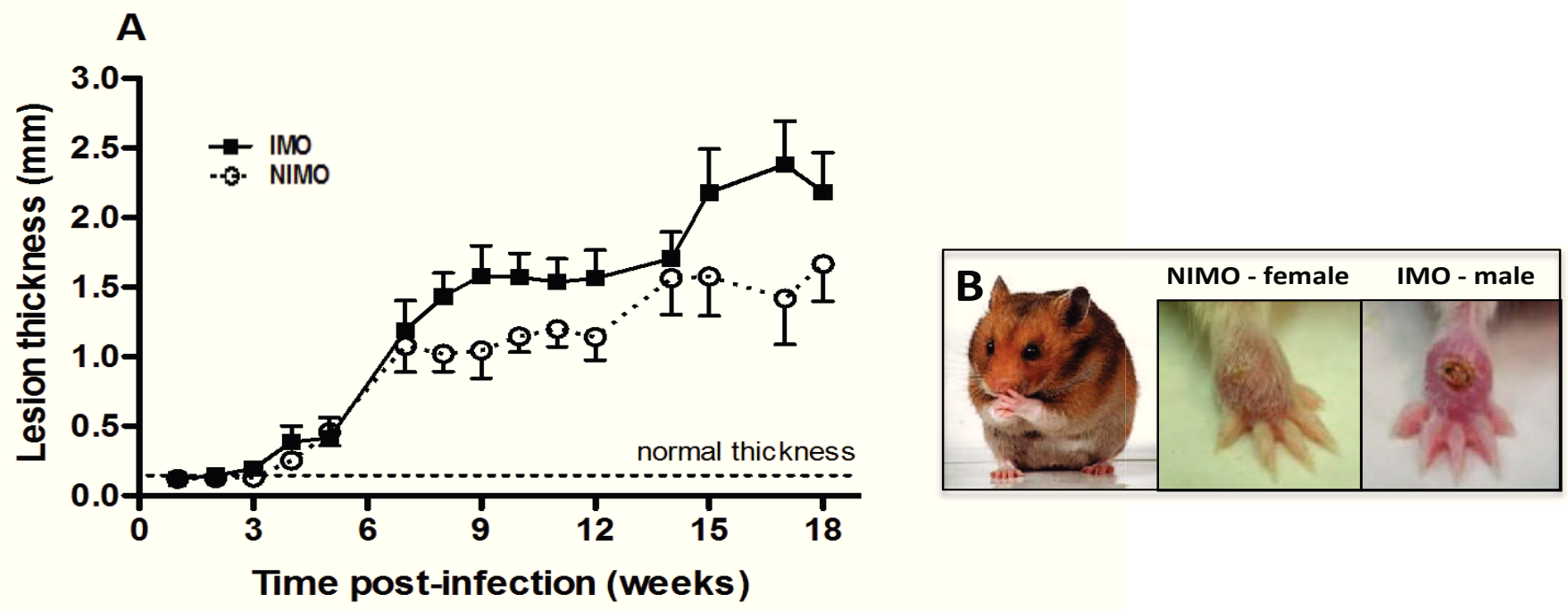

J. Health Biol Sci. 2017; 5(2):121-129 
Figure 2. Parasite load in the lymph node (A) and footpad (B) in hamster offspring infected with Leishmania braziliensis, born from infected (IMO) or non-infected mother (NIMO) at 5th, 9th and 17th weeks post-infection. Data are shown as arithmetic mean \pm standard error of the mean, and are representative of 2 independent experiments. Five animals were used in each group.
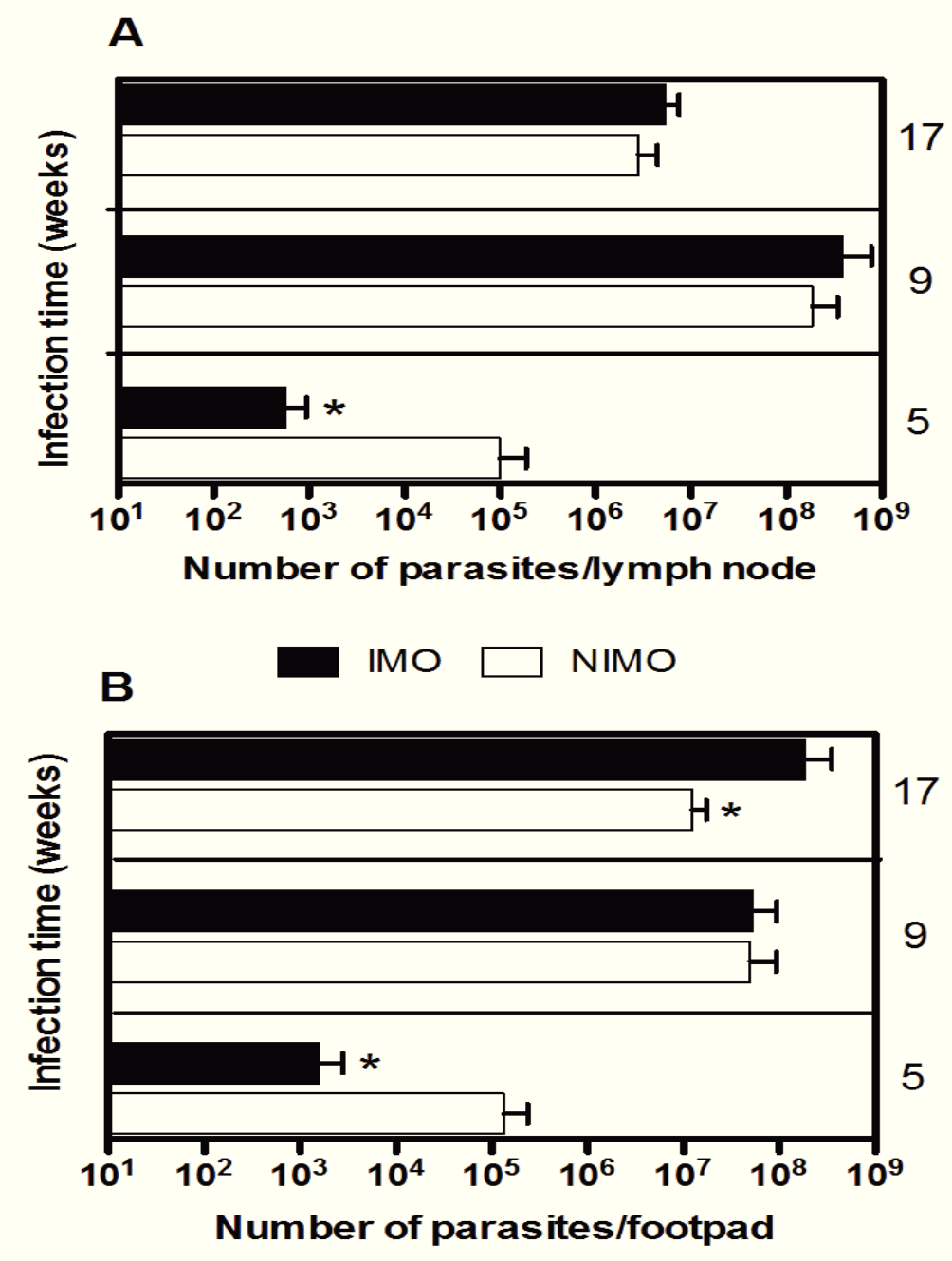

Figure 3. Quantification of anti-Leishmania antibodies in sera of hamsters (A) infected with Leishmania braziliensis, born of infected mother (NIMO) and non-infected mother (IMO) and (B) male offspring and female offspring. Each point represents the arithmetic mean of the absorbance \pm standard error of the mean. $\mathrm{N}=20$ (before infection and at the 4th week post-infection); $\mathrm{N}=15$ (8th week post-infection); $\mathrm{N}=10$ (12th and 16th weeks post-infection). Data are representative of 2 independent experiments.

A

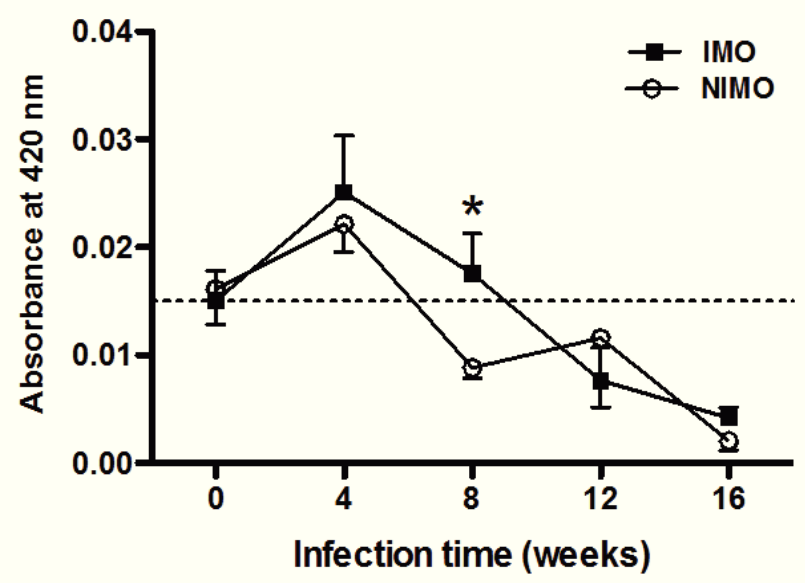

B

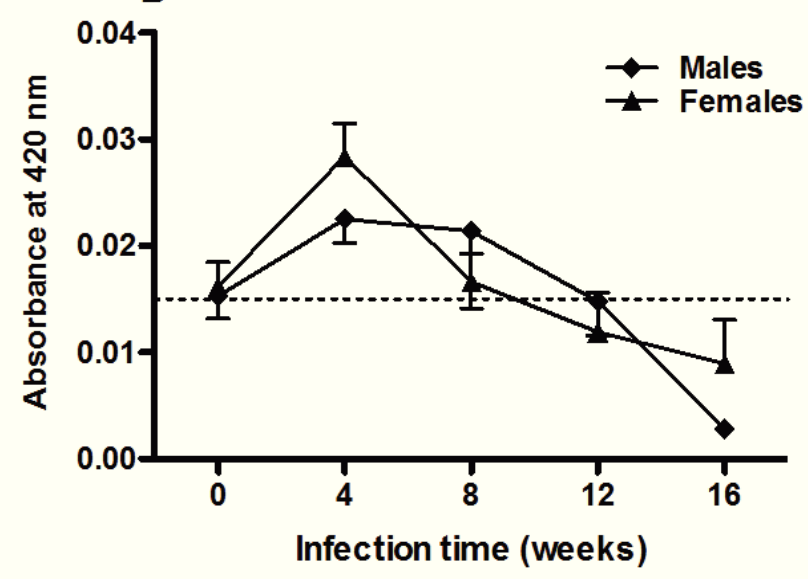


Influence of maternal infection - Analysis of the inflammatory reaction

The inflammatory reaction on the footpad after the $18^{\text {th }}$ week post-infection indicated that an infected mother offspring and a non-infected mother offspring presented moderate to intense cellular exudate, with a granulomatous reaction permeated by plasma cells and granulocytes (Fig.4C1, 4C2 and 4C3). The presence of neutrophils was always associated with foci of necrosis and presence of apoptotic bodies (Fig. 4C4). However, it was possible to distinguish small differences between both groups. Infected mother offspring group presented exudate with more macrophages and plasma cells than non-infected mother offspring (Fig 4A). Although both groups revealed a moderate amount of granulomas, the index organized/non-organized granuloma was lower in infected mother offspring, associated to more parasitism. In addition, in non-infected mother offspring we can notice a decreased parasitism associated with the presence of more granulomas (Fig. 4A).

When we included all analyzed parameters, the inflammatory reaction on the footpad lesion at the $18^{\text {th }}$ week infection indicated a prominent inflammatory response in infected mother offspring when compared to non-infected mother offspring ( $p<0.05)$ (Fig. 4B).

Figure 4. Inflammatory reaction (A), total score (B) of inflammation and Photomicrographs of histopathological changes (C) in the footpad in hamster offspring infected with Leishmania braziliensis, born from infected (IMO) or non-infected mother (NIMO), at 18th week post-infection. (A) Each bar represents the arithmetic average of the scores. (B) Each point represents the sum of the scores for the different inflammatory parameters and its associated average. Photomicrographs: C1. Infected mother offspring (IMO), HE 40X; C2. Non-infected mother offspring (NIMO), HE 40X; C3. Intense cellular exudate, with a granulomatous reaction permeated by plasma cells and granulocytes, HE 100X; C4. Foci of necrosis and presence of apoptotic bodies (black arrow), HE 400X.
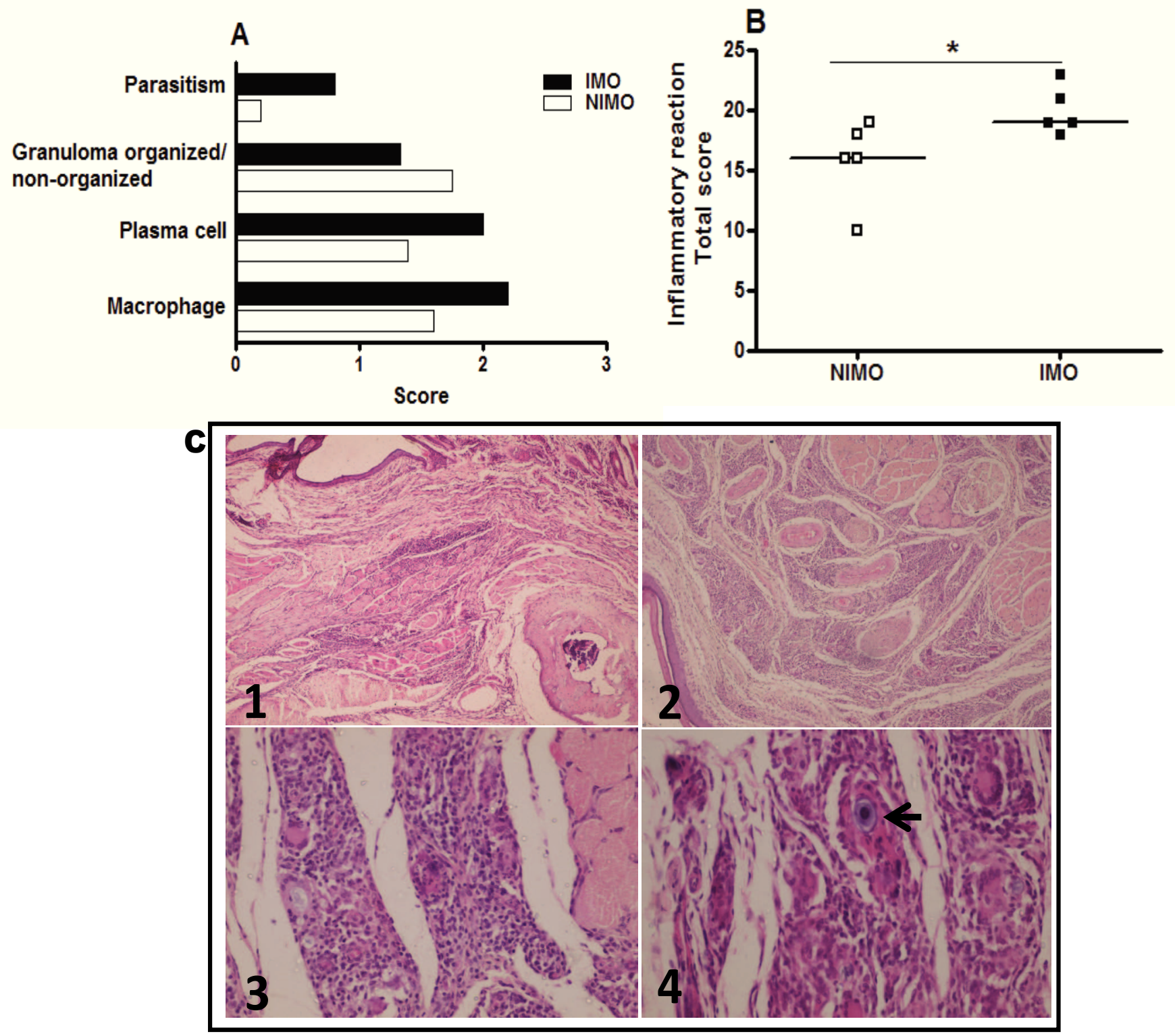

J. Health Biol Sci. 2017; 5(2):121-129 
Influence of gender - Lesion size, parasite load and antiLeishmania antibodies

A new analysis of the infection by L. braziliensis in hamster offspring was accomplished dividing the groups by gender. Results of the footpad lesions measurements indicated that male offspring had larger lesions, statistically significant on the $5^{\text {th }}, 9^{\text {th }}, 10^{\text {th }}$ and $18^{\text {th }}$ weeks post-infection $(p<0.05)$, when compared to females, independent of IMO or NIMO condition (Fig. 5A). Analyzing the parasite load in relation to gender, there was no significant difference on the number of parasites in the infected footpad and draining lymph node between male and females, except in the $5^{\text {th }}$ week post-infection (Fig. 5B and 5C).

When groups were separated by gender, anti-Leishmania antibodies were detected as early as the $4^{\text {th }}$ week post-infection in both groups, with discrete predominance in females, in this period. The amount of antibodies was higher in males only from the $8^{\text {th }}$ week and decreased later than in females, which in turn returned to normal rates at the 8 th week post infection (Fig. 3B).

Figure 5. Lesion thickness (A) and parasite load in the lymph node (B) and footpad (C) in male and female hamster offspring infected with Leishmania braziliensis. (A) Each point represents the arithmetic mean \pm standard error of the mean. $\mathrm{N}=20$ (1st to 5 th weeks post-infection). $\mathrm{N}=20$ (1st to 5 th week post-infection); $\mathrm{n}=16$ ( 7 th and 8 th week post-infection); $\mathrm{n}=12$ ( 12 th to 17 th week post-infection); $n=6$ (18th week post-infection). The dashed lines represent the normal thickness of 6 healthy animals (basal value). $(B$ and $C)$ Five to six animals were used in each group. Data are representative of 2 independent experiments.

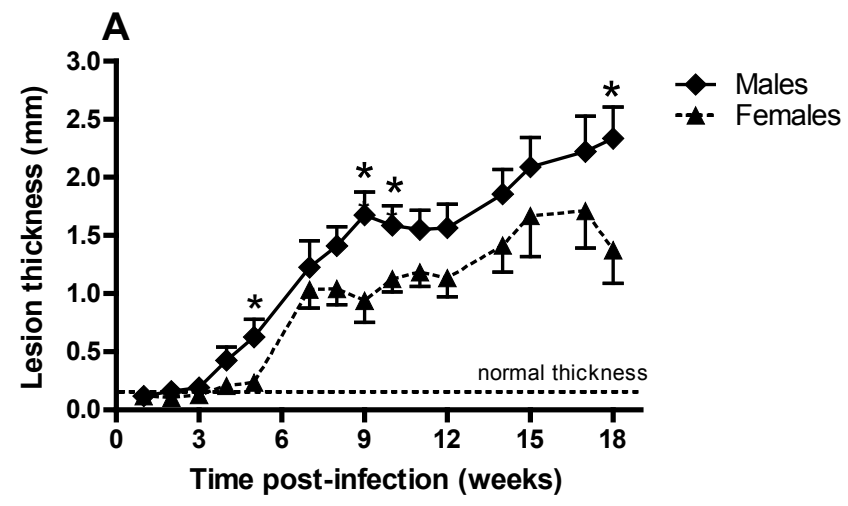

\section{B}

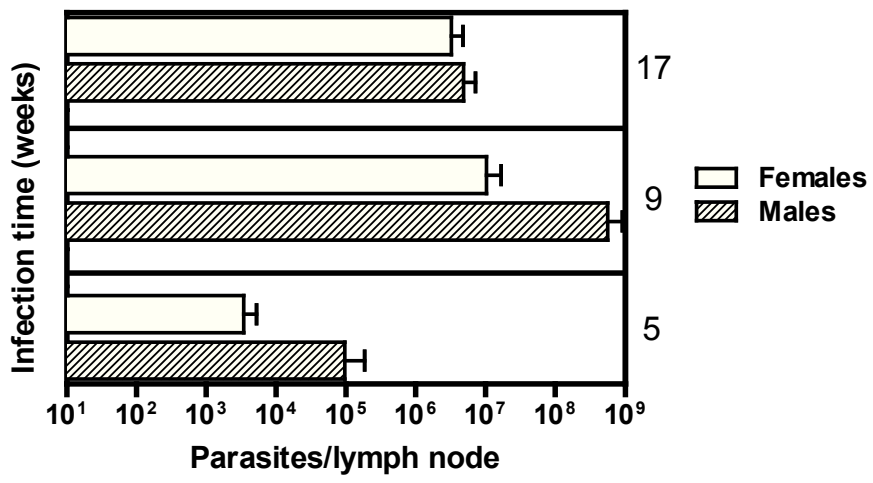

C

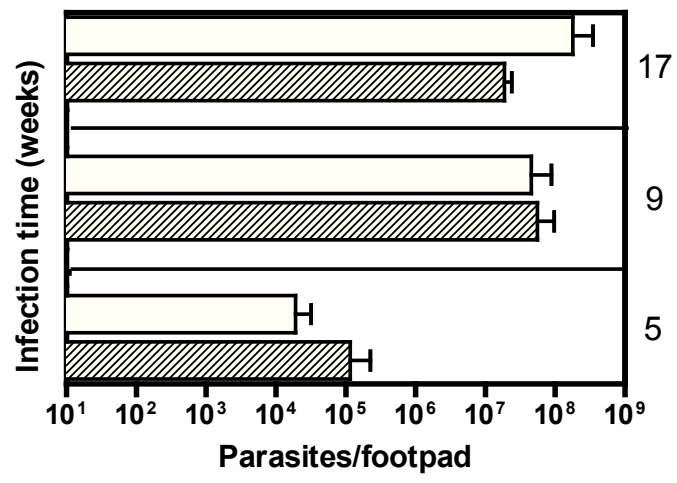

\section{DISCUSSION}

During pregnancy the immune response is modulated in order to avoid deleterious effects to the fetus. It is widely accepted that gestation is associated to lowered cellular immunity, including low pro-inflammatory cytokine expression and the activation of NK cells, preventing the occurrence of miscarriages ${ }^{15}$. However, the decreased adaptive immune response makes pregnant females more susceptible to a wide variety of pathogens, such as Leishmania ${ }^{15,16}$. Changes to the maternal immune system before and during pregnancy have revealed a capacity to modulate a neonatal immune response. The fetal sensitiveness mechanism is suggested as a result of maternal cell passage, vertical transmission of antigens and soluble factors transference ${ }^{17}$.

Herein, we evaluated whether the maternal infection by $L$. braziliensis in hamster could induce resistance or susceptibility 
to offspring when submitted to homologous infection. It has been known that animal susceptibility to infection depends on various factors, including the age of the host ${ }^{18}$. Infected animals in this present study were juveniles and prepubescent and presented a larger dissemination of parasites, and tendency to chronicity. Different studies reveal that susceptibility of young animals may be caused by less effective mechanisms in resolving the disease, resulting in an unsatisfactory macrophage activity in restricting the parasite growth. Young animals would have a decreased macrophage activity, a lowered and weakened intensity of response, a tendency to develop a Th2 response with prevalence of antibody production and poor defense mediated by cells ${ }^{19}$.

Even though previous studies reported a tendency to Th2 response during pregnancy and easiness in the transmission of antigens, cells or soluble factors via placenta ${ }^{7}$, we did not actually observe in this study the influence of maternal infection by $L$. braziliensis in the homologous offspring infection. There were no significant differences in lesion size or number of parasites (lesion and lymph node) in hamster offspring, regardless of whether they were born to an infected or a non-infected mother. Although the parasitic load in the IMO showed a significant decrease in the $5^{\text {th }}$ week post infection when compared to NIMO, however this lower number of parasites, both in the footpad and in the lymph node, did not correspond to the offspring clinical symptoms, since the disease maintained a chronic clinical course in both groups. The data from our study corroborate with studies performed with pregnant dogs infected by $L$. chagasi that have shown that despite the positive PCR test for Leishmania in placenta, there were no signs of disease transmission to the offspring ${ }^{20}$. Meanwhile, other authors believed that vertical transmission of L. infantum in humans could be possible ${ }^{21}$.

Previous studies have shown that in cutaneous infection in the hamster model aspects such as lymphadenopathy are observed, as well as in human infection ${ }^{22}$. The lymph node is an important site of proliferation of the parasite during infection, and one of the first organs affected during the systemic spread of the parasite. Leishmnia may persist within macrophages or fibroblasts of the draining lymph nodes for indefinite periods, thus helping in the persistence and modeling of the immune response ${ }^{23}$. The persistence of the disease and its consequences, such as the formation of metastatic lesions and/ or visceralization, typical of $L$. braziliensis, can be seen after three months of infection in the hamster model. Thus, it is possible to monitor the natural chronicity of the disease over long periods of time ${ }^{10}$. Herein, both animals born from infected mother and those from non-infected mother showed parasite load persistence in the lesions and lymph nodes.

In the present study, higher titers of anti-Leishmania IgG antibodies were observed in infected mother offspring already in the first weeks of infection. This highest number of antibodies anti-Leishmania in offspring born from infected mother correlates with the highest number of plasma cells observed in the histopathological analysis in the footpad of these animals. Even though this was not statistically significant, it is possible to correlate the major IgG titers in IMO with the highest lesions, parasite load and the inflammatory exudate. A possible explanation for our data could be the presence of the IgG4 isotype in the offspring born from infected mother that can induce a Th2 response, whereas in hamsters born from non-infected mother the present isotype would be $\lg \mathrm{G} 2$, which in turn induces Th1 response as already described ${ }^{24}$. It is known that IgG not only fails to promote intracellular pathogens, but also contributes to the progression of the disease by inducing macrophages to produce IL-10, which deactivates macrophage, instead of IL-12, a cytokine that together with other inflammatory mediators leads to disease control. Passive administration of anti-Leishmania IgG in BALB/C mice was correlated with increased IL-10 production, increasing the size and amount of parasites in the lesions ${ }^{25}$. As cytokines have not been evaluated in the present study, we can only suggest this as a possible explanation for our findings. Forthcoming studies evaluating the production of IgG isotypes and cytokines in this model could clarify this hypothesis.

Histopathology analysis at the $18^{\text {th }}$ week post-infection in IMO revealed a more inflammatory score, represented by tissue destruction associated with less fibrosis and increased frequency of macrophages, which are the host cells of Leishmania. These findings correlate with the ulcerated and chronic lesions found in these animals at the end of the experiment. Also, the index organized/non-organized granuloma was lower in infected mother offspring, associated to higher parasitism. In contrast, in animals born to non-infected mothers were seen more granulomas and less parasitism, and these findings correlate with the lower number of parasites found in the lesion of these animals at the $17^{\text {th }}$ weeks post-infection. It is worth noting that the IMO group also presented a slower reduction of antiLeishmania antibody titers, probably driven by a higher Th2 response, with a less effective cellular response, corroborated by a lower rate of organized/non-organized granuloma and greater parasitism.

Several studies have shown that humans and hamsters share several histopathological features in cutaneous Leishmaniasis caused by $L$. braziliensis ${ }^{11}$, including the presence of granulomas, which have already been well characterized in other studies involving the hamster model in L. braziliensis infection ${ }^{11,26,27}$. Also, studies have shown that control of the disease in mice infected Leishmania requires a coordinated response of the host, involving the development of granulomas around the infected macrophages ${ }^{28}$. However, the effectiveness of granulomas to kill the parasites depends on the degree of granuloma maturation ${ }^{28,29}$. Only mature granulomas develop efficient leishmanicidal mechanisms to kill the parasites ${ }^{30}$.

Analyzing data on gender and its influence on $L$. braziliensis infection, we observed that males presented larger lesion sizes than females. We reported also a superior parasite load on male offspring, yet not statistically different than females. 
Studies on mice BALB/C infected with L. major revealed that males developed larger lesions at earlier stages than females; however, after 90 days of infection, the increase was equivalent, leading to results similar to ours ${ }^{9}$. Different studies report that female hamsters were more resistant to cutaneous Leishmaniasis (L. mexicana and L. panamensis) than males, being such difference dependent on the levels of circulating sex hormones ${ }^{18}$. In hamsters infected by $L$. panamensis or $L$. guyaenesis an increased number of parasites in male lesions compared to females was reported. This same study revealed that males are more susceptible to infection by Leishmania of genus Viannia than females. Females treated with exogenous testosterone presented larger lesions than females without treatment and males. However, males treated with estrogen revealed no significant differences compared with untreated males $^{18}$. Probably the slightly larger lesions seen in animals born from infected mother in our study are associated with the larger lesions of male offspring that are more susceptible to Leishmania infection than females.

When we analyzed the titers of anti-Leishmania antibodies we observed presence these antibodies in the $4^{\text {th }}$ week postinfection in both male and female animals; however, these titers of antibodies remained higher for longer in males. We can again suggest the importance of IgG in the progression of the disease, corroborated by the significant increase in male lesions size, especially in the period in which the antibodies appeared, as well as the higher parasite load.
In conclusion, maternal infection by $L$. braziliensis in hamsters seems did not influence the course of the disease in the homologous offspring infection, and additionally male offspring presented an increased susceptibility to infection by $L$. braziliensis, independent of maternal condition before delivery (infected or non-infected), leading to a pattern of response more indolent than females. Additionally, the reduction of the organized/non-organized granuloma index observed in the lesion in offspring born from an infected mother, at the $18^{\text {th }}$ week post-infection, together with the higher inflammatory response, suggests a less effective cellular response in the chronic phase of the disease in these animals. It also can be suggested that a more intense inflammatory response in offspring from infected mother may possibly be correlated with an increased induction of inflammatory cells, cytokines and chemokines, though this particular aspect was not evaluated in this study and could be better investigated in future studies. It is still uncertain if a Th2 response during pregnancy may ease substance passage to the fetus that might interfere on the natural course of the disease to which offspring would be submitted experimentally. This work opens an avenue for future studies on the influence of Leishmania infection during pregnancy on progeny, especially in populations living in endemic areas for Leishmaniasis and which are always at risk of infection by these pathogens.

\section{Acknowledgments}

We wish to thank CNPq and Coordenação de Aperfeiçoamento de Pessoal de Nível Superior (CAPES) for fellowships.

\section{REFERENCES}

1. Piscopo TV, Mallia Azzopardi C. Leishmaniasis. Postgrad Med J. 2007 Feb; 83(976):649-57.

2. Vasconcelos IA, Vasconcelos AW, Momen H, Grimaldi G Jr, Alencar JE. Epidemiological Studies on American Leishmaniasis in Ceará State, Brazil. Molecular Characterization of Leishmania Isolate. Am Trop Med Parasitol. 1988 Dec;82(6):547-54

3. Pearson RD, Sousa AQ, Jeronimo SMB. Leishmania species: visceral (kalaazar), cutaneous, and mucosal Leishmaniasis. In: Mandell GL, Bennett J, Dolin $\mathrm{R}$, editors. Principles and Practice of Infections Diseases, 5th ed. New York: Elsevier; 2005. p. 3145-54.

4. Sousa AQ, Parise ME, Pompeu MM, Coehlo JM Filho, Vasconcelos IA, Lima JW, et al. Bubonic Leishmaniasis: a common manifestation of Leishmania (Viannia) braziliensis infection in Ceará, Brazil. Am J Trop Med Hyg. 1995 Oct; 53(4):38085.

5. Barral A, Guerreiro J, Bomfim G, Correia D, Barral-Netto M, Carvalho EM. Lymphadenopathy as the first sign of human cutaneous infection by Leishmania braziliensis. Am J Trop Med Hyg. 1995 Sep; 53(3):256-59. PMID: 7573708.

6. Carlier $Y$, Truyens $C$. Influence of maternal infection on offspring resistance towards parasites. Parasitol Today. 1995 Mar; 11(3):94-99.

7. Krishnan L, Guilbert LJ, Russell AS, Wegmann TG, Mosmann TR, Belosevic M. Pregnancy impairs resistance of $\mathrm{C} 57 \mathrm{BL} / 6$ mice to Leishmania major infection and causes decreased antigen-specific IFN- $\gamma$ response and increased production of T helper 2 cytokines. J Immunol. 1996 Jan;156(2):644-52.

8. Klein SL. Hormonal and immunological mechanisms mediating sex differences in parasite infection. Parasite Immunol. 2004 Jun-Jul; 2696-7):247-64.
9. Mock BA, Nacy CA. Hormonal modulation of sex differences in resistance to Leishmania major systemic infections. Infect Immun. 1988; 56(12):3316-19. PMCID PMC259743.

10. Oliveira $\mathrm{Cl}$, Teixeira MJ, Gomes R, Barral A, Brodskyn C. Animal models for infectious diseases caused by parasites: Leishmaniasis. Drug Discov Today Dis Models. 2004 Oct;1:81-86. doi: http://dx.doi.org/10.1016/j. ddmod.2004.07.005.

11. Ribeiro-Romão RP, Moreira OC, Osorio EY, Cysne-Finkelstein L, GomesSilva A, Valverde JG, Pirmez C, Da-Cruz AM, Pinto EF. Comparative evaluation of lesion development, tissue damage, and cytokine expression in golden hamsters (Mesocricetus auratus) infected by inocula with different Leishmania (Viannia) braziliensis concentrations. Infect Immun. 2014 Dec;82(12):5203-13.

12. Teixeira MJ, Fernandes JD, Teixeira CR, Andrade BB, Pompeu ML, Santana da Silva J, Brodskyn Cl, Barral-Netto M, Barral A. Distinct Leishmania braziliensis isolates induce different paces of chemokine expression patterns. Infect Immun. 2005 Feb; 73(2):1191-95. doi: 10.1128/IAI.73.2.1191-1195.2005.

13. Taswell, C. Limiting dilution assays for the determination of immunocompetent cell frequencies III. Validity tests for the single-hit Poisson model. J Immunol Methods. 1984 Aug; 72(1):29-40.

14. Evans, TG, Vasconcelos IA, Lima JW, Teixeira JM, McAullife IT, Lopes UG, Pearson RD, Vasconcelos AW. Canine visceral Leishmaniasis in northeast Brazil: assessment of diagnostic methods. Am. J. Trop. Med. Hyg. 1990 Feb; 42(2):11823. PMID: 2156463

15. Osorio Y, Bonilla DL, Peniche AG, Melby PC, Travi BL. Pregnancy enhances the innate immune response in experimental cutaneous Leishmaniasis through hormone-modulated nitric oxide production. J Leukoc Biol. 2008 Jun; 83(6): 1413-22. doi: 10.1189/jlb.0207130. 
16. Figueiró-Filho EA, Duarte G, El-Beitune P, Quintana SM, Maia TL. Visceral Leishmaniasis (kala-azar) and pregnancy. Infect Dis Obstet Gynecol. 2004;12(1):31-40. doi: 10.1080/1064744042000210384

17. Fagoaga OR, Nehlsen-Cannarela SL. Maternal modulation of neonatal immune system development. Dev Immunol. 2002 Mar; 9(1):9-17. PubMed PMID: 12353663.

18. Travi B, Osorio Y, Melby P, Chandrasekar B, Arteaga L, Saravia N. Gender is a major determinant of the clinical evolution and immune response in hamsters infected with Leishmania spp. Infect. Immun 2002; 70:2288-96.

19. Singh N, Samant M, Gupta SK, Kumar A, Dube A. Age-influenced population kinetics and immunological responses of Leishmania donovani in hamsters. Parasitol Res. 2007 Sep; 101(4):919-24. doi: 10.1007/s00436-007-0562-3.

20. Andrade HM, de Toledo VP, Marques MJ, França Silva JC, Tafuri WL, Mayrink W, Genaro O. Leishmania (Leishmania) chagasi is not vertically transmitted in dogs. Vet Parasitol. 2002 Jan;103(1-2):71-81.

21. Meinecke CK, Schottelius J, Oskam L, Fleischer B. Congenital transmission of visceral Leishmaniasis (Kala Azar) from an asymptomatic mother to her child. Pediatrics. 1999;104(5): e65. PubMed PMID: 10545591.

22. Hommel M, Jaffe CL, Travi B, Milon G. Experimental models for Leishmaniasis and for testing anti-Leishmanial vaccines. Ann Trop Med Parasitol. 1995;89:5573.

23. Moll H, Flohé S, Blank C. Dendritic cells seclude Leishmania parasites that persist in cured mice - a role in the maintenance of T-cell memory? Adv Exp Med Biol. 1995;378:507-9. PMID: 8526129
24. Rocha RDR. Acesso de documento primário: Aplicações da pesquisa de anticorpos IgG anti-formas promastigotas vivas de Leishmania (V.) braziliensis, por citometria de fluxo, em estudos clínicos da leishmaniose cutânea localizada. 2005. Tese (Doutorado em Biologia Celular e Molecular) - Instituto Oswaldo Cruz, Belo Horizonte, 2005.

25. Miles SA, Conrad SM, Alves RG, Jeronimo SM, Mosser DM. A role for IgG immune complexes during infection with the intracellular pathogen Leishmania. J Exp Med. 2005 Mar 7;201(5):747-54. PMID:15753208

26. Kahl L, Byram J, David J, Comerford S, Von Lichtenberg F. Leishmania (Viannia) braziliensis: Comparative pathology of Golden Hamsters infected with isolates from cutaneous and mucosal lesions of patientes residing in Tres Bracos, Bahia, Brazil. Am J Trop Med Hyg. 1991; 44:218-32.

27. Sinagra A, Riarte A, Luna C, Campanini A, Segura EL. Leishmania (Viannia) braziliensis: biological behavior in golden hamsters of isolates from argentine patients. Am J Trop Med Hyg. 1997: 57(1):115-18.

28. Murray HW. Tissue granuloma structure-function in experimental visceral Leishmaniasis. Int J Exp Pathol. 2001; 82(5): 249-67.

29. Carrión J, Nieto A, Iborra S, Iniesta V, Soto M, Folgueira C, Abanades DR Requena JM, Alonso C. Immunohistological features of visceral Leishmaniasis in BALB/c mice. Parasite Immunol. 2006; 28(5): 173-83.

30. Nieto A, Domínguez-Bernal G, Orden JA, De La Fuente R, Madrid-Elena N, Carrión J. Mechanisms of resistance and susceptibility to experimental visceral leishmaniosis: BALB/c mouse versus syrian hamster model. Vet Res. 2011; 42: 39.

\section{Como citar este artigo/How to cite this article:}

Lima LFA, Frutuoso MS, Oliveira ACA, Figueiredo WME, Pompeu MML, Teixeira MJ. Maternal infection by Leishmania braziliensis in hamster does not influence the course of disease in progeny. J Health Biol Sci. 2017 Abr-Jun; 5(2):121-129. 